\title{
Production of a surface-localized oxidant during oxygenation of mackinawite (FeS)
}

Jie He ${ }^{1,2}$, Christopher J. Miller ${ }^{2}$, Richard Collins ${ }^{2}$, Dongsheng Wang ${ }^{1}$ and T. David Waite $2,3^{*}$

${ }^{1}$ Key Laboratory of Drinking Water Science and Technology, Research Center for Eco-Environmental Sciences, Chinese Academy of Sciences, Beijing 100085, China.

${ }^{2}$ UNSW Water Research Centre, School of Civil and Environmental Engineering, UNSW Sydney, NSW, 2052, Australia.

${ }^{3}$ Shanghai Institute of Pollution Control and Ecological Security, School of Environmental Science and Engineering, Tongji University, Shanghai 200092, P. R. China.

(Supplementary Information containg 22 pages and 18 figures)

* Corresponding author: Professor T. David Waite; E-mail: d.waite@unsw.edu.au 


\section{S1. Chemicals}

Sodium sulfide nonahydrate $\left(\mathrm{Na}_{2} \mathrm{~S} \cdot 9 \mathrm{H}_{2} \mathrm{O}, \geq 99.99 \%\right)$, iron (III) nitrate nonahydrate $\left(\mathrm{Fe}\left(\mathrm{NO}_{3}\right)_{3} \cdot 9 \mathrm{H}_{2} \mathrm{O}, \geq\right.$ $98 \%$ ), sodium hydroxide $(\mathrm{NaOH}, \geq 97 \%)$, hydrogen peroxide solution $\left(\mathrm{H}_{2} \mathrm{O}_{2}, 30\right.$ wt. \% in $\left.\mathrm{H}_{2} \mathrm{O}\right)$, benzoic acid (BA, $99.5 \%)$, sodium benzoate (99.5\%), salicylic acid (SA, 99+ \%), 4-hydroxybenzoic acid (4-HBA, $99 \%$ ), 3hydroxybenzoic acid (3-HBA, $99 \%$ ), 2,5-dihydroxybenzoic acid (2,5-DHBA, $98 \%$ ), sodium bicarbonate $\left(\mathrm{NaHCO}_{3}\right.$, > $99 \%)$, 4-(2-hydroxyethyl) piperazine-1-ethanesulfonic acid (HEPES, > $99 \%$ ), phenol ( $\geq 99.5 \%), 1,2-$ dihydroxybenzene (catechol, $\geq 99 \%$ ), resorcinol (99\%), hydroquinone (99\%), 1,4-benzoquinone (98\%), 2,3dihydroxybenzoic acid (2,3-DHBA, 99 \%), 2,4-dihydroxybenzoic acid (2,4-DHBA, 97 \%), 2,6-dihydroxybenzoic acid (2,6-DHBA, 98 \%), 3,4-dihydroxybenzoic acid (3,4-DHBA, 97 \%), 3,5-dihydroxybenzoic acid (3,5-DHBA, 97 \%), Lascorbic acid ( $\geq 99 \%$ ), deuterium oxide (99.9 atom \% D), 3-(2-Pyridyl)-5,6-diphenyl-1,2,4-triazine-p,p'-disulfonic acid monosodium salt hydrate (ferrozine, $97 \%$ ) and formic acid ( $\geq 98 \%$ ) were all purchased from Sigma-Aldrich. Iron (II) sulphate $\left(\mathrm{FeSO}_{4} \cdot 7 \mathrm{H}_{2} \mathrm{O},>99.0 \%\right)$ and perchloric acid $\left(\mathrm{HClO}_{4}, 70 \%\right)$ were purchased from Univar. Potassium hydroxide pellet $(\mathrm{KOH},>85.0 \%)$ and ethanol (100\%) was purchased from chem-supply. Hydrochloric acid ( $\mathrm{HCl}, 32 \%$ ) and acetonitrile (HPLC grade) were purchased from RCI Labscan. Diethylenetriamine-pentaacetic acid (DTPA, $\geq 99 \%$ ) and $p$-benzoquinone ( $\geq 99.5 \%$ ) were purchased from Fluka. Methanol (HPLC grade) was purchased from Scharlau. Benzene (99.7\%) was purchased from BDH. Tert-butanol (TBA, >99\%) was purchased from Unilab. 


\section{S2. Synthesis of FeS and 2-line ferrihydrite}

FeS was synthesized in an anaerobic chamber. A total of $24 \mathrm{~mL}$ of approximately $1.1 \mathrm{M} \mathrm{Na}{ }_{2} \mathrm{~S}$ was slowly added to $40 \mathrm{~mL}$ of $0.57 \mathrm{M} \mathrm{FeSO}_{4}$ under stirring. The resulting slurry was aged for 3 days, followed by centrifugation at $10000 \mathrm{rpm}$ for $5 \mathrm{~min}$. The black precipitates, FeS, were then washed with deoxygenated MQ and separated by centrifugation 8 times. Finally, FeS was dried, ground to a powder and stored in the anaerobic chamber.

2-line ferrihydrite was synthesized by adding approximately $68 \mathrm{~mL}$ of $1 \mathrm{M} \mathrm{KOH}$ to $100 \mathrm{~mL}$ of $0.2 \mathrm{M}$ $\mathrm{Fe}\left(\mathrm{NO}_{3}\right)_{3}$ under stirring at a $\mathrm{pH}$ around 7. The last $4 \mathrm{~mL}$ of $\mathrm{KOH}$ was added dropwise with constant checking of $\mathrm{pH}$. The reddish brown ferrihydrite precipitate was separated by centrifugation at $4200 \mathrm{rpm}$ for 4 min, then washed with $\mathrm{pH} 4 \mathrm{HCl} 9$ times before final re-suspension in the buffer solution (20 mM HEPES and $1 \mathrm{mM} \mathrm{NaHCO}_{3}$, $\mathrm{pH} 8.00 \pm 0.01)$. Use of $\mathrm{pH} 4 \mathrm{HCl}$ ensured $\mathrm{pH}$ below the point of zero charge $(\mathrm{pzc})$ of ferrihydrite, ${ }^{1}$ enabling resuspension when washing. Some ferrihydrite was freeze-dried for XRD analysis. The concentration of the final suspension was determined by measuring Fe(II) concentration spectrophotometrically ${ }^{2}$ after complete reductive dissolution according to Jones et al. ${ }^{3} ; 50 \mu \mathrm{L}$ of well-mixed ferrihydrite final suspension was added to $10 \mathrm{~mL} 0.1$ $\mathrm{M}$ of $\mathrm{L}$-ascorbic acid solution, stirred for $2 \mathrm{~h}$ until complete dissolution, and then added to the buffered ferrozine solution for measurement.

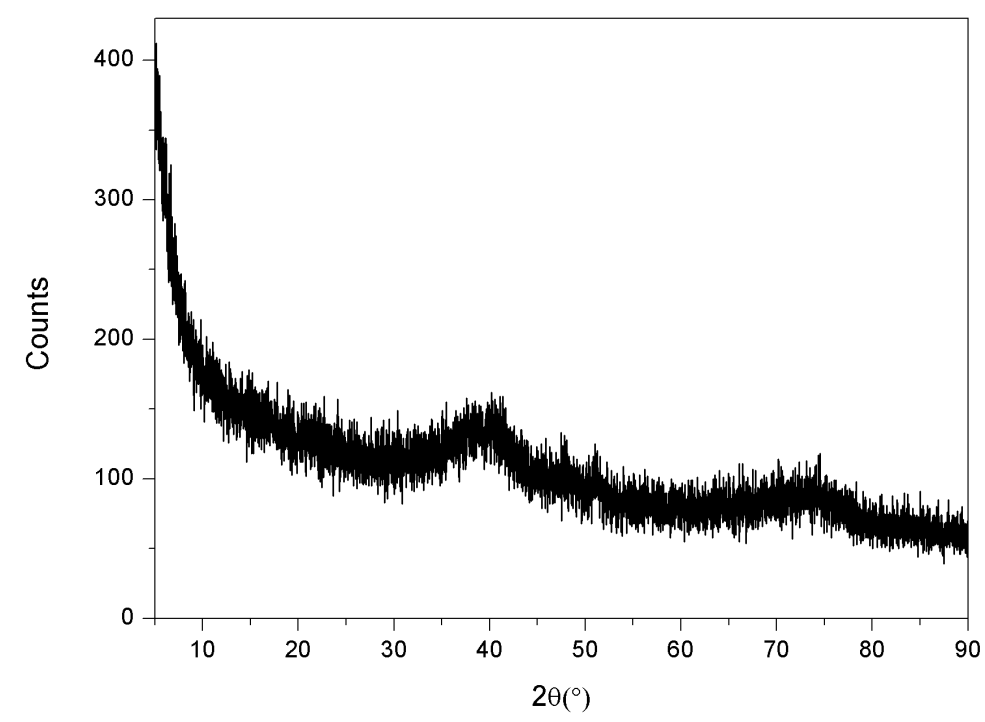

Figure S1. XRD pattern of the synthesized 2-line ferrihydrite. 


\section{S3. Comparison experiments}

The acidic homogeous Fenton reaction was initiated by adding $\mathrm{H}_{2} \mathrm{O}_{2}$ into $1.17 \mathrm{mM}$ of $\mathrm{HClO}_{4}$ solution $\left(\mathrm{pH}_{0} 3.00 \pm 0.01\right)$ with approximately $5.0 \mathrm{mM}$ of $\mathrm{BA}$ and $10.40 \mu \mathrm{M}$ of $\mathrm{FeSO}_{4}$. The solution of circumneutral $\mathrm{pH}$ homogeous Fenton reaction was prepared by adding $9.96 \mathrm{mM}$ of DTPA solution of $\mathrm{pH} 8.00 \pm 0.01$ and then 4.84 $\mathrm{mM}$ of $\mathrm{FeSO}_{4}$ solution into the buffer solution containing approximately $5.0 \mathrm{mM}$ of $\mathrm{BA}$, which was mixed for a few seconds to form the Fe(II)-DTPA complex. $\mathrm{H}_{2} \mathrm{O}_{2}$ was then added to initiate the reaction.

A ferrihydrite-catalyzed heterogeneous Fenton reaction at $\mathrm{pH} 7.5$ was initiated by adding $\mathrm{H}_{2} \mathrm{O}_{2}$ into the buffer solution containing approximately $5.0 \mathrm{mM}$ of BA and $6.95 \mathrm{mM}$ of $\mathrm{Fe}(\mathrm{III})$-equivalent ferrihydrite. The ferrihydrite-catalyzed heterogeneous Fenton reaction with Fe(II)-DTPA was conducted as for the circumneutral homogeneous Fenton reaction, except that the buffer solution contained $5 \mathrm{mM}$ of BA and also $6.95 \mathrm{mM}$ of Fe(III)-equivalent ferrihydrite. In order to prevent long-term evaporation, air was passed through a Dreschel bottle containing MQ before being purged into the reaction Dreschel bottle.

For these comparison experiments, $1 \mathrm{~mL}$ of suspension was pipetted and quickly quenched with $50 \mu \mathrm{L}$ of methanol at determined time intervals, which was then centrifuged at 13,000 rpm for 3 min. The supernatant was collected for analysis. 


\section{S4. Analytical Procedures}

BA, hydroxybenzoic acids (HO-BAs), catechol and other possible oxidation products in the reaction supernatant were separated and analyzed using an Agilent series 1100 high performance liquid chromatography (HPLC) with both UV and fluorescence detection. An XDB-C18 column ( $5 \mu \mathrm{m}, 4.6 \mathrm{~mm} \times 150 \mathrm{~mm})$ was used at ambient room temperature $\left(20^{\circ} \mathrm{C}\right)$. Mobile phase $\mathrm{A}$ of $\mathrm{pH} 2$ formic acid and mobile phase $\mathrm{B}$ of acetonitrile were used throughout with the flow rate maintained at $1 \mathrm{~mL} / \mathrm{min}$. Unless specified, the gradient conditions for analyzing the BA oxidation samples were as follows: 0-13 min, $10 \% \mathrm{~B} ; 13-15 \mathrm{~min}, 10-30 \% \mathrm{~B} ; 15-23 \mathrm{~min}, 30 \% \mathrm{~B}$; 23-25 min, 30-60 \% B; 25-30 min, 60 \% B; 30-31 min, 60-100 \% B; 31-35 min, 100 \% B; 35-36 min, 100-10 \% B; 36-40 min, $10 \%$ B. SA oxidation samples were analysed by isocratic elution using $15 \%$ B for 30 min. An injection volume of $50 \mu \mathrm{L}$ was used in all cases. Due to the acidity of the eluent, $\mathrm{BA}, \mathrm{SA}$ and the oxidation products were eluted as the corresponding protonated compounds. The detection wavelength of UV was set at $276 \mathrm{~nm}$ for BA, 4-hydroxybenzoic acid (4-HBA) and catechol, at $300 \mathrm{~nm}$ for 3-hydroxybenzoic acid (3-HBA), at $330 \mathrm{~nm}$ for 2,5DHBA and at $315 \mathrm{~nm}$ for 2,3-dihydroxybenzic acid (2,3-DHBA). SA was quantified by fluorescence $\left(\lambda_{\mathrm{ex}}=314 \mathrm{~nm}\right.$, $\left.\lambda_{\mathrm{em}}=400 \mathrm{~nm}\right)$.

The solid products arising from the reaction of $2.5 \mathrm{~g} / \mathrm{L} \mathrm{FeS}$ and $5.0 \mathrm{mM} \mathrm{BA}$ after 5-h oxygenation were separated by centrifugation, followed by drying, grinding and storage in an anaerobic chamber prior to being subjected to an array of solid phase analyses.

For XRD measurements, the synthesized FeS was sealed in an XRD sample holder in the anaerobic chamber and then transferred to the XRD instrument for analysis.

HRTEM and STEM-EDX were performed on a JEOL JEM-F200 cold field-emission gun scanning/transmission electron microscope operated with an accelerating voltage of $200 \mathrm{kV}$. EDX spectra were obtained with a windowless JEOL silicon drift EDX detector and EDX data were analysed using Thermo Scientific Pathfinder software. Samples for TEM analysis were prepared using the dropcast technique in an anaerobic chamber. The synthesized FeS powder was re-dispersed in ethanol using an ultrasonic bath for $0.5 \mathrm{~h}$ and the suspension dropcast onto a holey carbon TEM grid and dried in the anaerobic chamber. The sample grid was transported to the HRTEM in a micro-centrifuge tube sealed in the anaerobic chamber and only briefly exposed to air to mount into the TEM sample holder.

Iron K-edge XAS spectroscopy were collected in transmission mode on the XAS beamline at the Australian Synchrotron (Melbourne, Australia). The beam was sourced from a 1.9 T wiggler, the beam energy selected using a double-crystal fixed exit $\mathrm{Si}(311)$ monochromator, and the beam fully tuned with a rhodiumcoated toroidal mirror. Samples and references were mixed with boron nitride in an anaerobic chamber to a final Fe concentration of approximately $7 \mathrm{wt} \%$, then pressed into aluminium holders and covered with $63.5 \mu \mathrm{m}$ Kapton film windows. Samples were transported to the synchrotron in air-tight containers and only opened to mount the sample holders for analysis. To prevent sample transformation during analysis, samples were analyzed at room temperatrure under a He atmosphere. A thin foil of elemental Fe was analyzed simultaneously with the sample and reference lepidocrocite to correct for any energy shifts during analysis. Both XANES and EXAFS data were extracted from the X-ray absorption spectroscopy spectra using Athena, with background subtraction accomplished with the default parameters of the Autobk algorithm. 

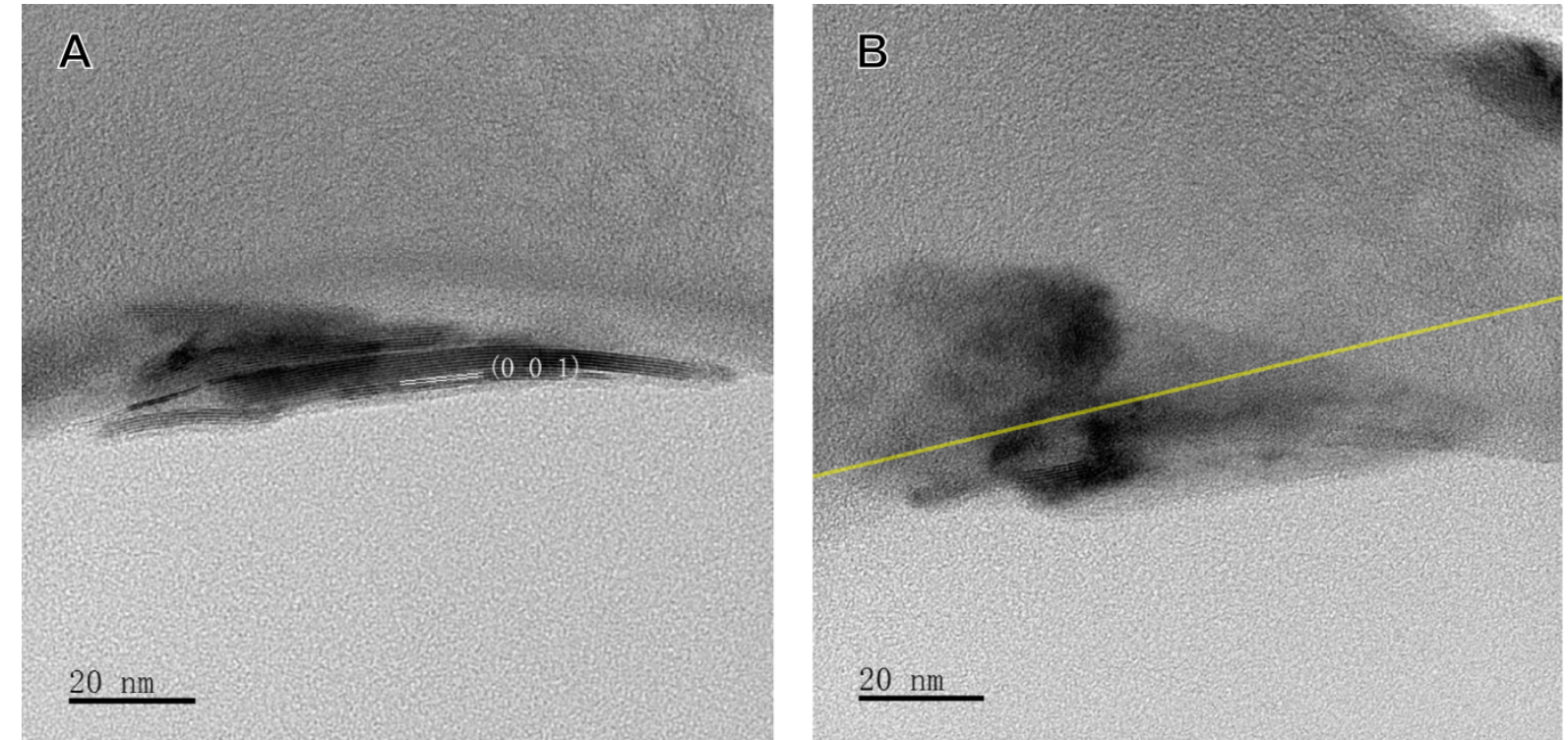

Figure S2. HRTEM images of $(A)$ the synthesized FeS showing lattice spacing and $(B)$ the same particle after tilting the sample along the yellow line at $30^{\circ}$ relative to $(A)$. 

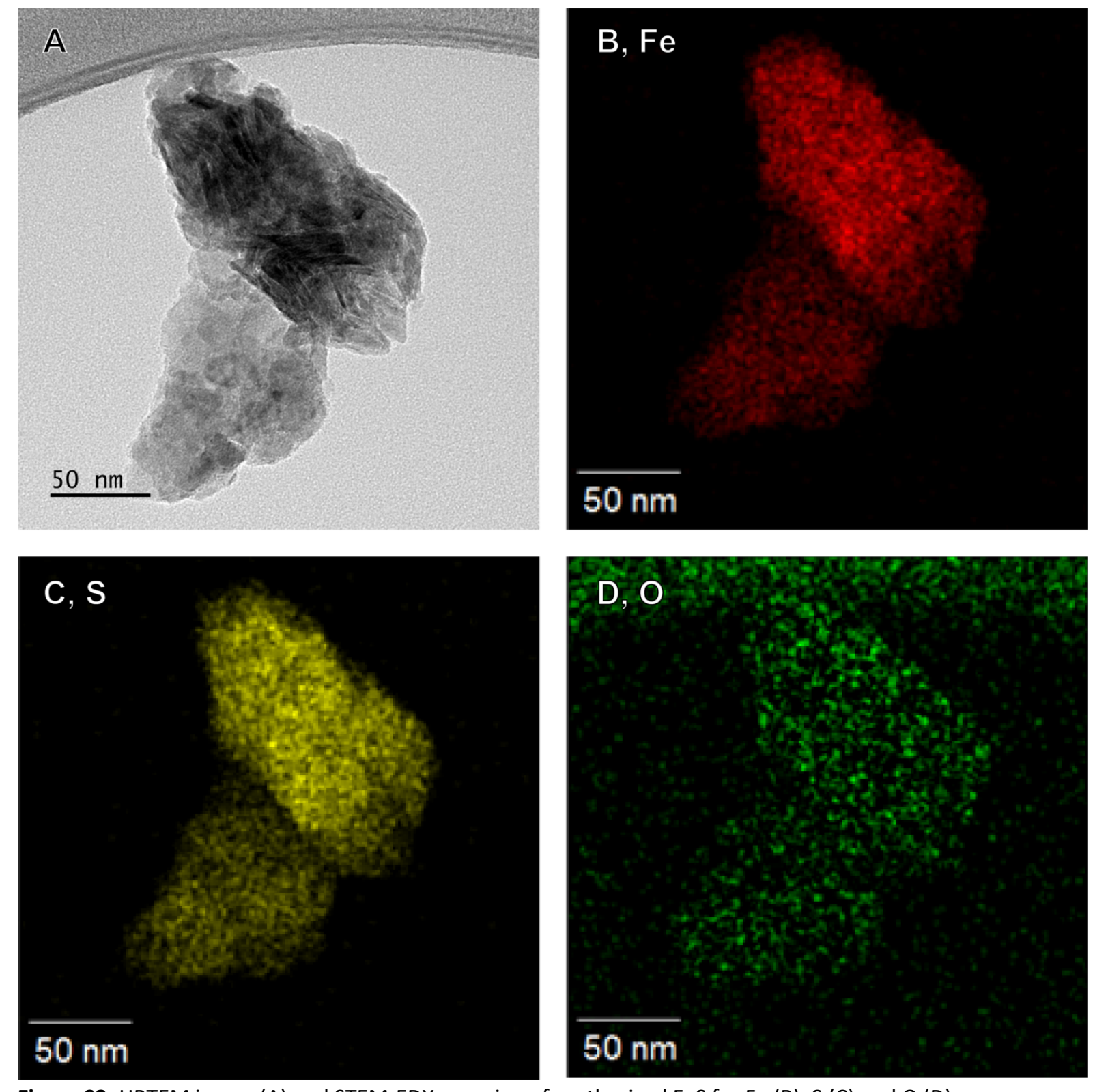

Figure S3. HRTEM image (A) and STEM-EDX mapping of synthesized FeS for Fe (B), S (C) and O (D). 


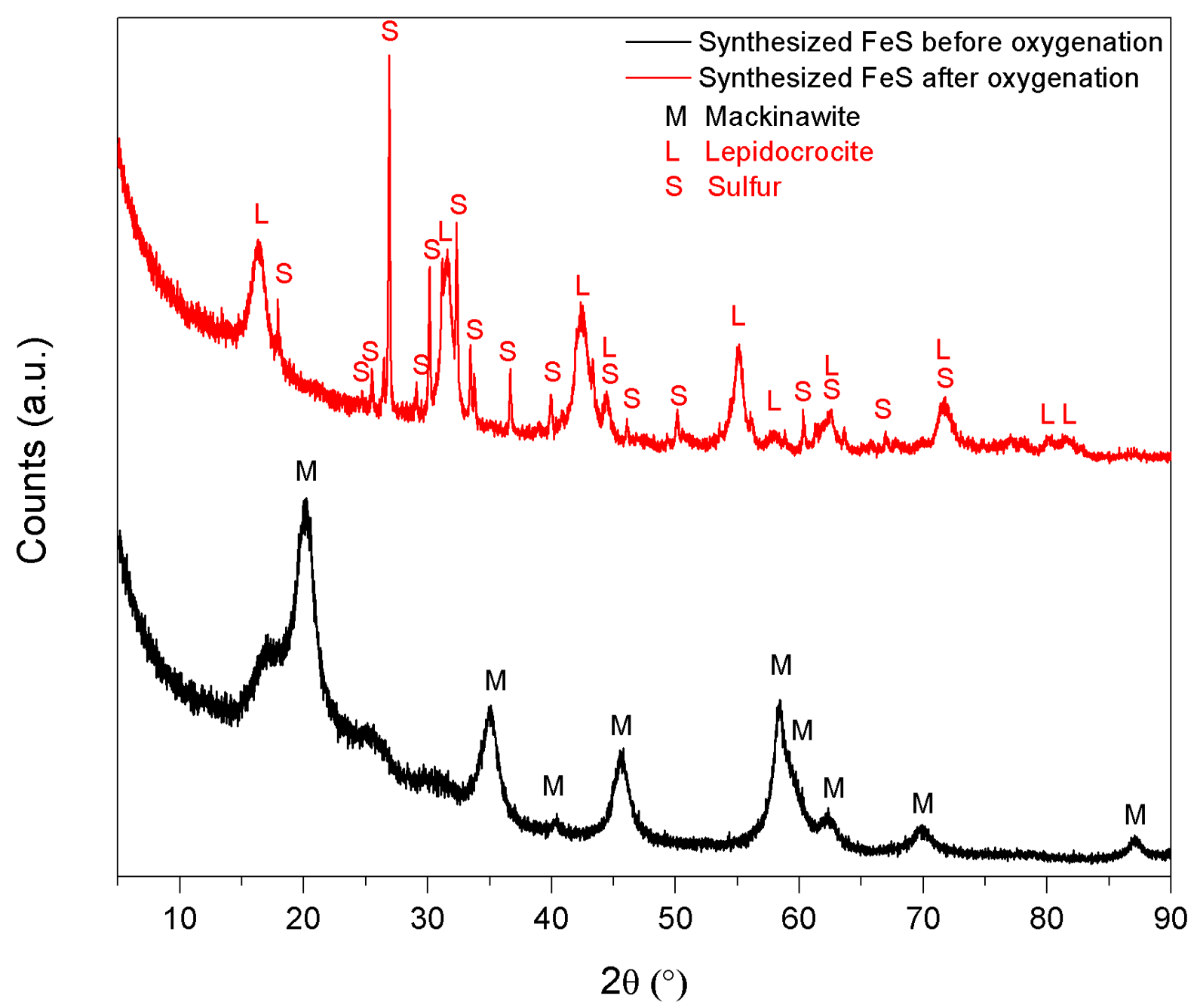

Figure S4. XRD patterns of the synthesized FeS before and after oxygenation. The typical peaks of sulfur and lepidocrocite were consistent with the standard XRD patterns of ICSD card 98-020-0453 and ICDD card 04-0143986 , respectively. 


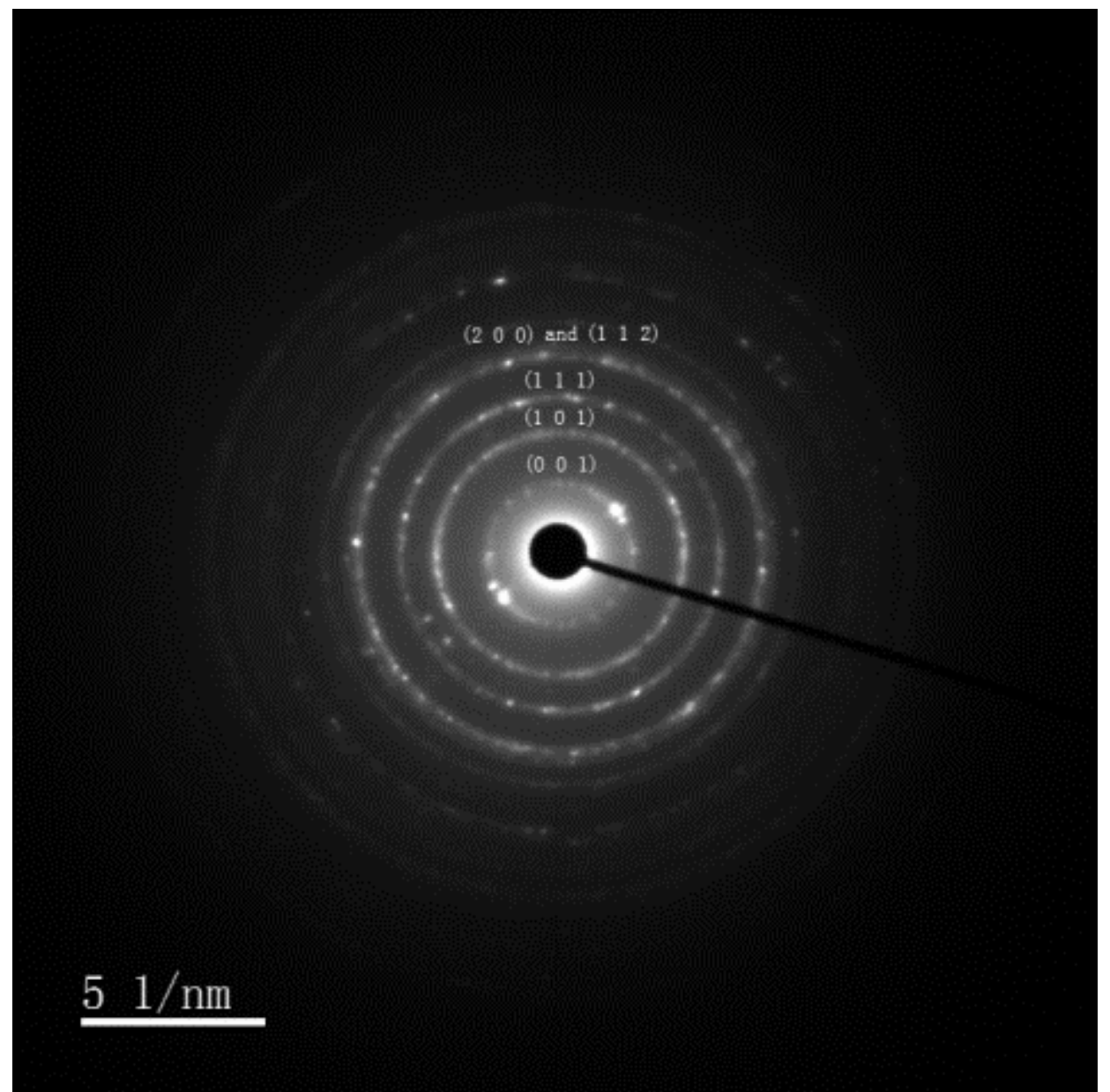

Figure S5. Selected area electron diffraction (SAED) pattern of the synthesized FeS. 

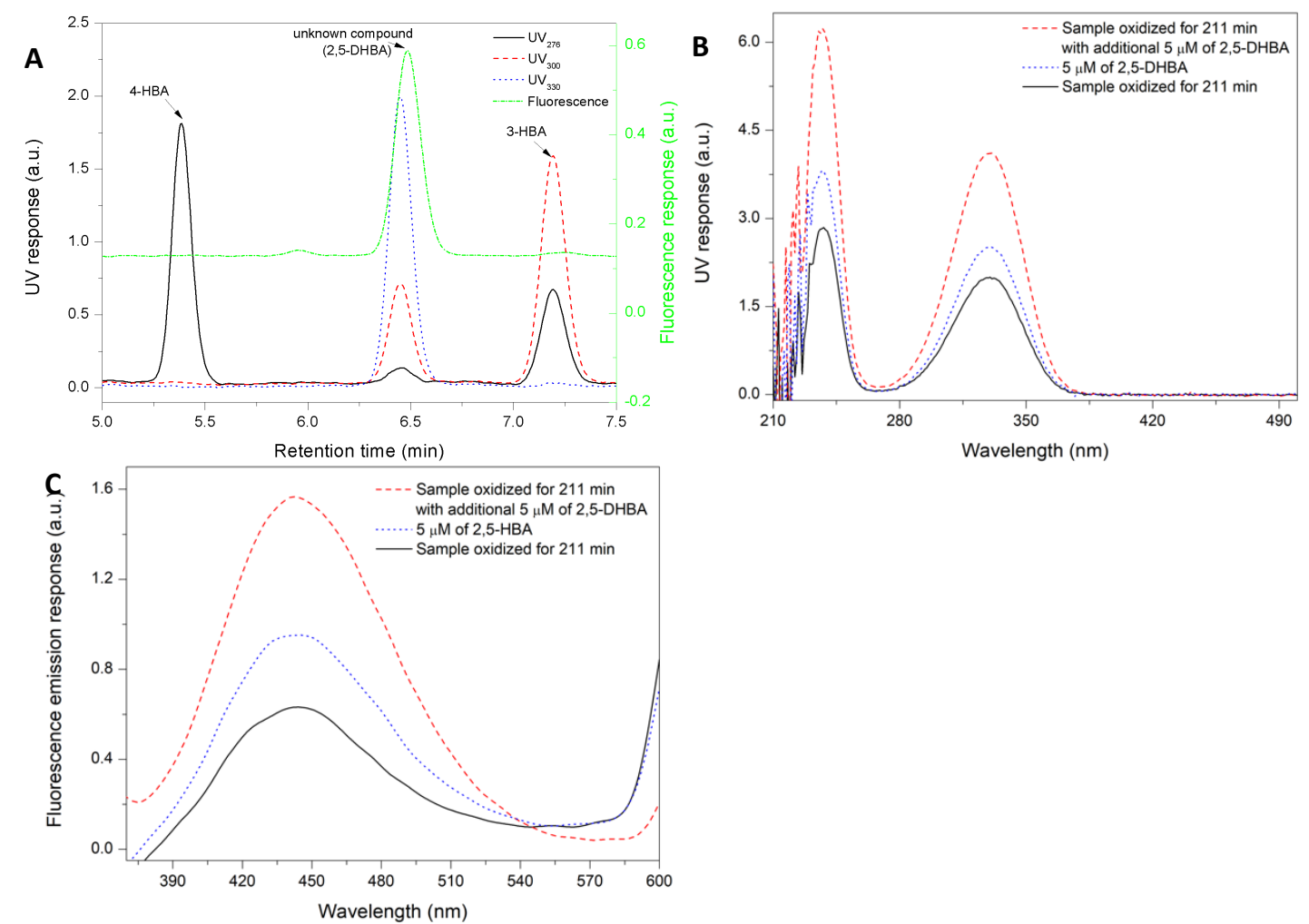

Figure S6. (A) Part of HPLC profile of BA oxidation sample during FeS oxygenation. Oxidation time is $211 \mathrm{~min}$. Comparison of (B) UV scan and (C) fluorescence emission scan at $\lambda_{\mathrm{ex}}=314 \mathrm{~nm}$ at retention time $6.45 \mathrm{~min}$ of different samples. 


\section{S5. Examination of possibility of ${ }^{1} \mathrm{O}_{2}$ as non-hydroxyl radical oxidant}

Kalyanaraman et al. ${ }^{4}$ have reported 2,5-DHBA as the exclusive product formed during SA oxidation by ${ }^{1} \mathrm{O}_{2}$ in photochemical systems. They proposed that ${ }^{1} \mathrm{O}_{2}$ reacts with $\mathrm{SA}$ through an endoperoxide intermediate, while $\mathrm{HO}^{*}$ added to SA was mediated by a cyclohexadienyl radical. Considering the longer lifetime of ${ }^{1} \mathrm{O}_{2}$ in $\mathrm{D}_{2} \mathrm{O}$ $(22-70 \mu \mathrm{s})$ than in $\mathrm{H}_{2} \mathrm{O}(2.9-4.6 \mu \mathrm{s}),{ }^{5}$ much more 2,5-DHBA should be produced during FeS oxygenation in $\mathrm{D}_{2} \mathrm{O}$ if ${ }^{1} \mathrm{O}_{2}$ was the non-hydroxyl radical oxidant (Kalyanaraman et al. ${ }^{4}$ observed a factor of 8 increase in 2,5-DHBA production when $\mathrm{D}_{2} \mathrm{O}$ was used). However, when the FeS experiments were performed in $\mathrm{D}_{2} \mathrm{O}$, there was no obvious difference in BA oxidation product formation (Figure S7), suggesting that singlet oxygen is not the strong oxidant formed in the FeS system.

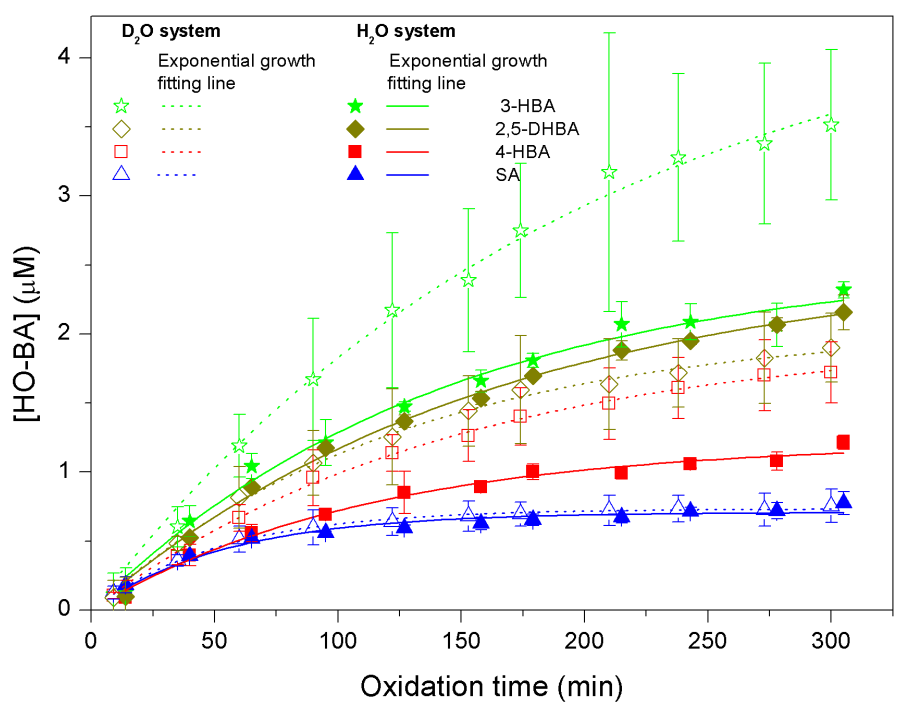

Figure S7. Comparison of BA oxidation during FeS oxygenation in $\mathrm{D}_{2} \mathrm{O}$ system and in $\mathrm{H}_{2} \mathrm{O}$ system. [FeS $]_{0}=0.9 \mathrm{~g} / \mathrm{L}$, $[B A]_{0}=5.0 \mathrm{mM}$ in $\mathrm{H}_{2} \mathrm{O}$ system, $4.5 \mathrm{mM}$ in $\mathrm{D}_{2} \mathrm{O}$ system, $[\mathrm{HEPES}]_{0}=20 \mathrm{mM},\left[\mathrm{NaHCO}_{3}\right]_{0}=1 \mathrm{mM}, \mathrm{pH}_{0} 8.0$. 

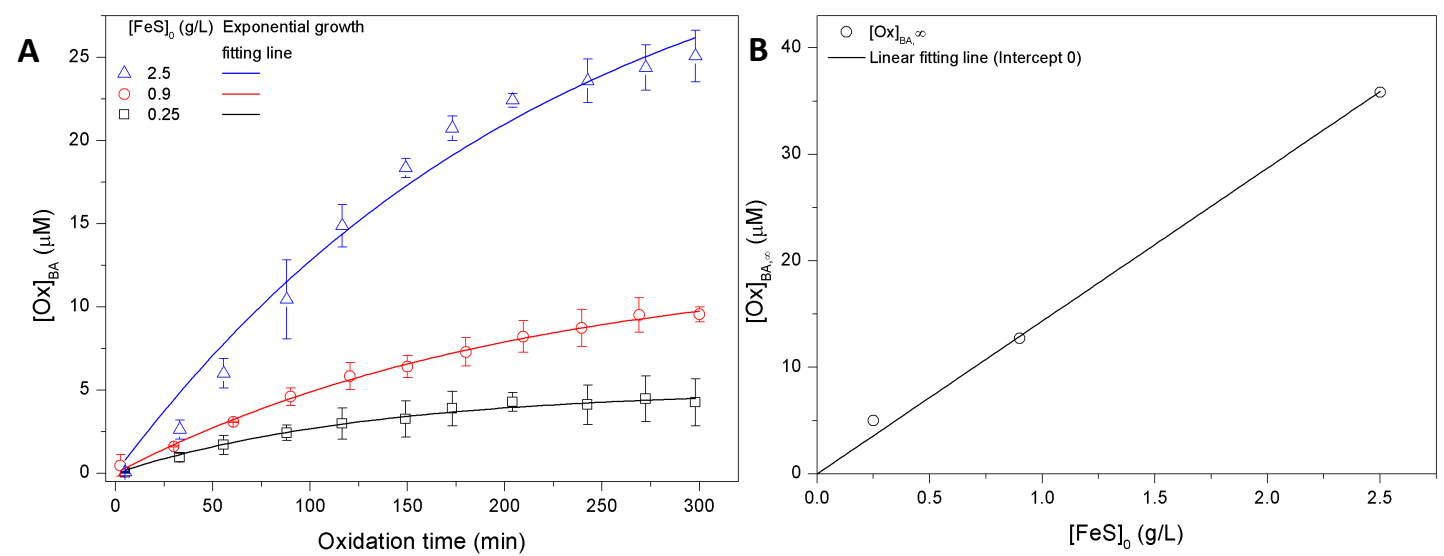

Figure S8. (A) Oxidation of BA during FeS oxygenation under varied $[\mathrm{FeS}]_{0}$. (B) Change of $[\mathrm{Ox}]_{\mathrm{BA}, \infty}$ with $[\mathrm{FeS}]_{0}$. $[B A]_{0}=5.0 \mathrm{mM},[\mathrm{HEPES}]_{0}=20 \mathrm{mM},\left[\mathrm{NaHCO}_{3}\right]_{0}=1 \mathrm{mM}, \mathrm{pH}_{0} 8.0$. 

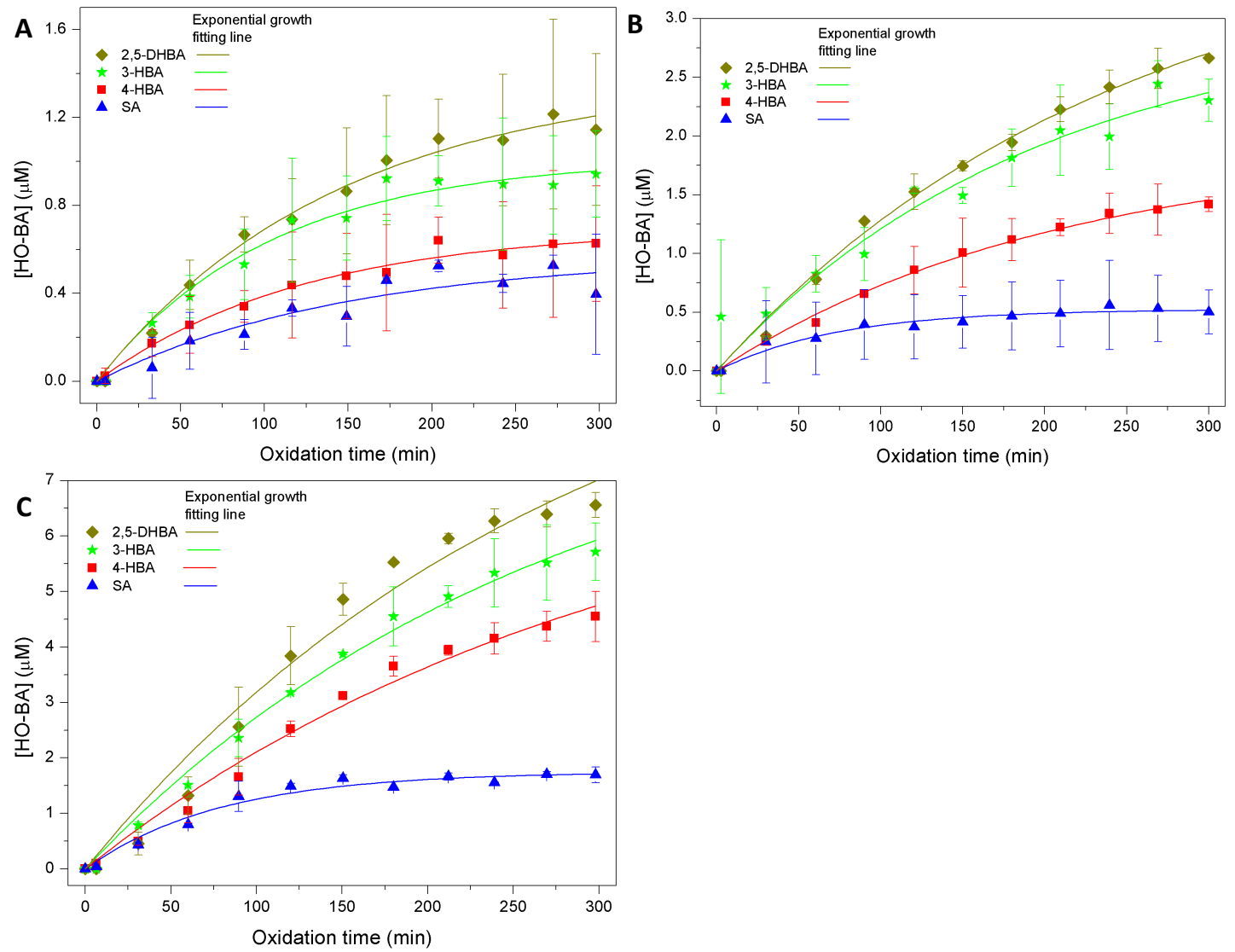

Figure S9. Oxidation of BA during FeS oxygenation under varied $[\mathrm{FeS}]_{0}:(\mathrm{A}) 0.25$, (B) $0.9,(\mathrm{C}) 2.5 \mathrm{~g} / \mathrm{L}$. $[\mathrm{BA}]_{0}=5.0$ $\mathrm{mM},[\mathrm{HEPES}]_{0}=20 \mathrm{mM},\left[\mathrm{NaHCO}_{3}\right]_{0}=1 \mathrm{mM}, \mathrm{pH}_{0} 8.0$. 

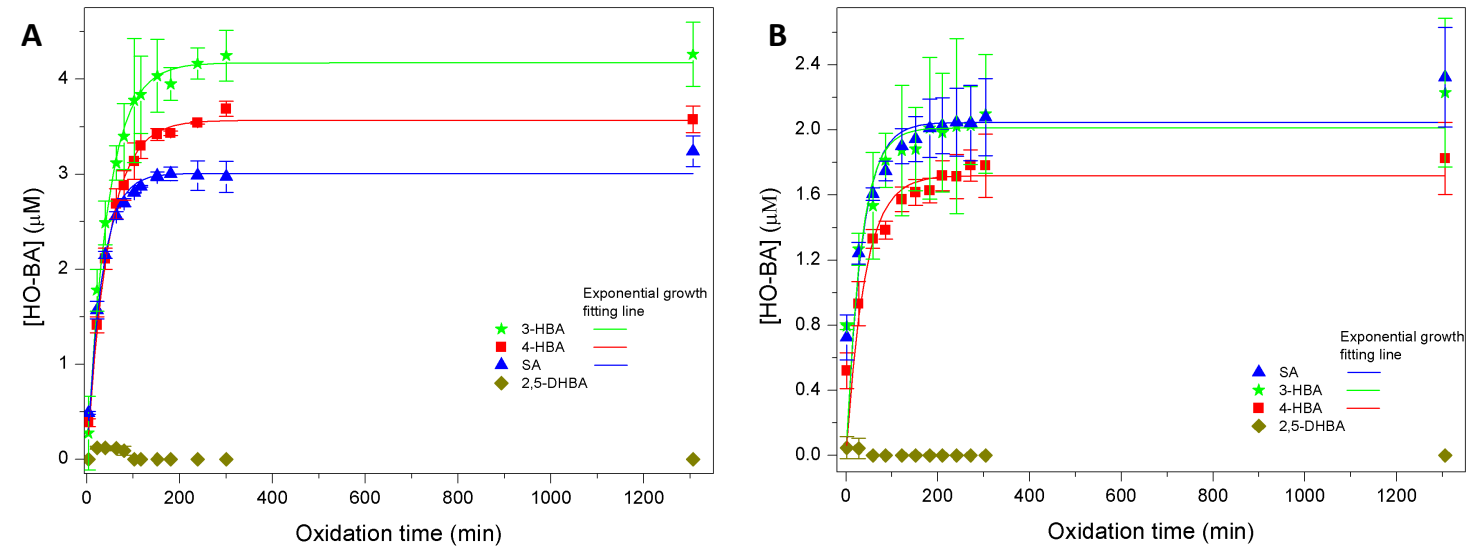

Figure S10. Long-term oxidation of BA in the aerated heterogeneous Fenton reactions catalyzed by ferrihydrite with and without the additional Fe(II)-DTPA. In all experiments, [ferrihydrite $]_{0}=6.95 \mathrm{mM}$ as Fe(III), [HEPES $]_{0}=$ $20 \mathrm{mM},\left[\mathrm{NaHCO}_{3}\right]_{0}=1 \mathrm{mM}, \mathrm{pH}_{0}$ 7.5. (A) $\left[\mathrm{H}_{2} \mathrm{O}_{2}\right]_{0}=2.2 \mathrm{mM},[\mathrm{BA}]_{0}=4.9 \mathrm{mM}$. (B) $[\mathrm{Fe}(\mathrm{II})]_{0}=112 \mu \mathrm{M},[\mathrm{DTPA}]_{0}=222$ $\mu \mathrm{M},\left[\mathrm{H}_{2} \mathrm{O}_{2}\right]_{0}=500 \mu \mathrm{M},[\mathrm{BA}]_{0}=4.4 \mathrm{mM}$. 


\section{S6. Examination of adsorption of hydroxybenzoates to iron oxide and recovery}

The role of adsorption was examined through control experiments where known amounts of hydroxybenzotes were added to synthetic ferrihydrite and the solution phase composition examined (Figure S11). For moderately adsorbed species such as 2,5-DHBA and SA, this was sufficient, however, for strongly adsorbed 2,3DHBA solution phase concentrations were too low for reliable extrapolation of solution concentration to total (i.e., solution + adsorbed) concentrations. Under conditions otherwise similar to those in Figure S11, only 1.5 $\mu \mathrm{M}$ remained in solution after addition of $60 \mu \mathrm{M}$ 2,3-DHBA. As the amount of hydroxybenzoates adsorbed was proportional (as demonstrated by constant percent adsorbed as a function of adsorbate concentration, inset of Figure S11), at total 2,3-DHBA concentrations potentially produced during an FeS oxidation experiment, the amount remaining in solution would also be too low to quantify. As such, attempts were made to analyse the adsorbed materials by dissolution of the solid iron oxide phase with ascorbic acid.

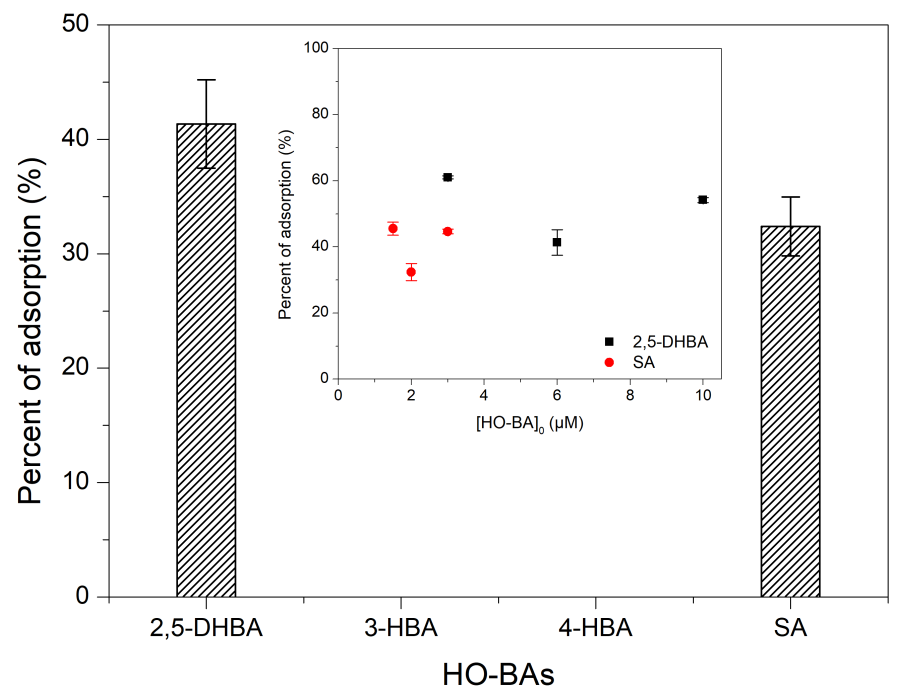

Figure S11. Percent of adsorption of HO-BAs on ferrihydrite after 5 h. [ferrihydrite $]_{0}=6.95 \mathrm{mM}$ as Fe(III), $[\mathrm{BA}]_{0}$ $=5 \mathrm{mM},[2,5-\mathrm{DHBA}]_{0}=6 \mu \mathrm{M},[3-\mathrm{HBA}]_{0}=4 \mu \mathrm{M},[4-\mathrm{HBA}]_{0}=4 \mu \mathrm{M},[\mathrm{SA}]_{0}=2 \mu \mathrm{M},[\mathrm{HEPES}]_{0}=20 \mathrm{mM},\left[\mathrm{NaHCO}_{3}\right]_{0}=1$ $\mathrm{mM}, \mathrm{pH}_{0}$ 7.5. Insert: [ferrihydrite $]_{0}=6.95 \mathrm{mM}$ as Fe(III), $[\mathrm{HEPES}]_{0}=20 \mathrm{mM},\left[\mathrm{NaHCO}_{3}\right]_{0}=1 \mathrm{mM}, \mathrm{pH}_{0} 7.5,[\mathrm{BA}]_{0}=$ $5 \mathrm{mM}$ with either 2,5-DHBA or SA.

The ascorbic acid dissolution method was performed as follows. $1 \mathrm{M}$ ascorbic acid solution was prepared by dissolving $17.6 \mathrm{~g} \mathrm{~L}$-ascorbic acid in $100 \mathrm{~mL}$ Milli-Q water which was heated for a few minutes until complete dissolution. The suspension from an oxidation or adsorption experiment was then centrifuged at $13000 \mathrm{rpm}$ for $3 \mathrm{~min}$. $1 \mathrm{~mL}$ supernatant was injected to HPLC while the other supernatants were discarded. All the precipitates in one reactor were collected and transferred to a $50 \mathrm{~mL}$ corning centrifuge tube by rinsing with 1 $\mathrm{M}$ ascorbic acid solution $(10 \mathrm{~mL}$ ). The sintered Dreschel bottle head (from the FeS oxidation vessel) was then added and the centrifuge tube sealed and wrapped with aluminium foil, followed by shaking for about $34 \mathrm{~h}$ for complete dissolution. Finally, the supernatant ( $\mathrm{pH} \sim 2.9$ ) after centrifugation at $13000 \mathrm{rpm}$ for $3 \mathrm{~min}$ (to remove elemental sulfur) was injected to HPLC to analyze the solid phase. Control experiments were conducted similarly, with the desired concentration of hydroxybenzoates first added to the centrifuge tube, followed by the $1 \mathrm{M}$ ascorbic acid. Finally, iron was added either from solid $\mathrm{Fe}\left(\mathrm{NO}_{3}\right)_{3} \cdot 9 \mathrm{H}_{2} \mathrm{O}$ or from freshlycentrifuged ferrihdrite that was suspended in a buffer consisting of $20 \mathrm{mM} \mathrm{HEPES}$ and $1 \mathrm{mM} \mathrm{NaHCO}$ at $\mathrm{pH} 8$.

Control experiments were undertaken where a mixed solution containing BA, SA, 3-HBA, 4-HBA, 2,3-DHBA and 2,5-DHBA at concentrations similar to those present during the solid-dissolution experiment of the oxidized FeS in BA oxidation (the "BA" controls) as well as with a mixed solution containing catechol, 2,3-DHBA, 2,5DHBA and SA at concentrations similar to those present during the solid-dissolution experiment of the oxidized $\mathrm{FeS}$ in SA oxidation (the "SA" controls) were performed to assess the suitability of this method. Good recovery 
of hydroxybenzoates was found by this method in the absence of iron (Figures S12A and B), however, when $\mathrm{Fe}(\mathrm{III})$ was present (either added from ferric salts or from ferrihydrite) at the same concentration as that in an FeS oxidation experiments, significant interference/aberrant behaviour was found. In the BA controls, monohydroxybenzoates and 2,5-DHBA were artefactually produced from BA, presumably due to oxidation by $\mathrm{Fe}(\mathrm{III}),{ }^{6}$ however reasonable recovery of 2,3-DHBA was found. This suggests the ascorbic acid reduction method may be suitable for assessing 2,3-DHBA, although caution should be taken considering the clearly reactive nature of this system for the other analytes. For the SA control experiments, although Fe(III) addition did lead to some additional production of catechol, 2,3-DHBA and 2,5-DHBA, the changes in concentration were generally within $\pm 20 \%$. Despite Fe(III) clearly leading to some interference with this procedure, the method was still applied to FeS oxidation experiments of both BA and SA (Figure S13). Although quantifiable total concentrations could not be reliably estimated, it did allow for demonstration of whether or not any 2,3DHBA was formed; the results should however be interpreted with caution.
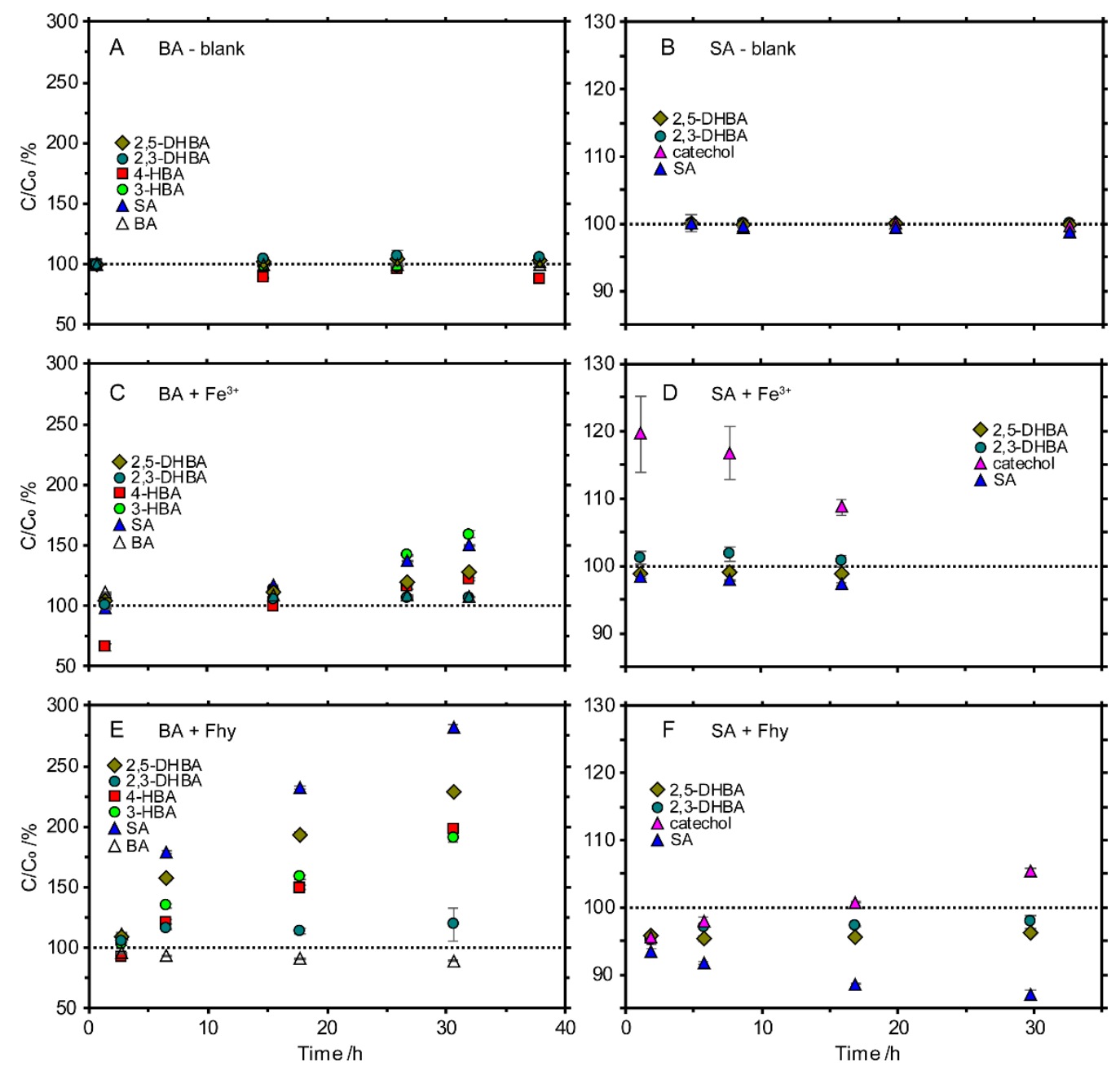

Figure S12. Recoveries of benzoate and salicylate oxidation products using the ascorbic acid reduction method for the BA control experiments $\left(\mathrm{A}, \mathrm{C}, \mathrm{E} ;[4-\mathrm{HBA}]_{0}=3 \mu \mathrm{M},[3-\mathrm{HBA}]_{0}=5 \mu \mathrm{M},[\mathrm{SA}]_{0}=7 \mu \mathrm{M},[2,5-\mathrm{DHBA}]_{0}=13 \mu \mathrm{M}\right.$, $\left.[2,3-D H B A]_{0}=2 \mu \mathrm{M},[B A]_{0}=1 \mathrm{mM},[A A]_{0}=0.9 \mathrm{M}\right)$ and the $S A$ control experiments $\left(B, D, F ;[\text { catechol }]_{0}=110 \mu \mathrm{M}\right.$, $\left.[2,3-\mathrm{DHBA}]_{0}=250 \mu \mathrm{M},[2,5-\mathrm{DHBA}]_{0}=150 \mu \mathrm{M},[\mathrm{SA}]_{0}=0.5 \mathrm{mM}\right)$. Panels $A$ and $B$ show the blank recoveries (i.e., ascorbic acid only), panels $B$ and $C$ show the impact of added $80 \mathrm{mM} \mathrm{Fe}\left(\mathrm{NO}_{3}\right)_{3} \cdot 9 \mathrm{H}_{2} \mathrm{O}$ and panels $\mathrm{E}$ and $\mathrm{F}$ the impact of added $50 \mathrm{mM}$ ferrihydrite. 
A

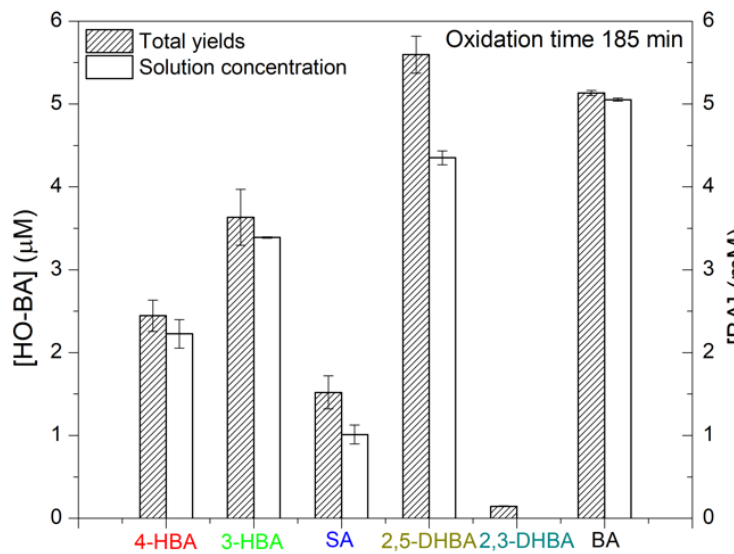

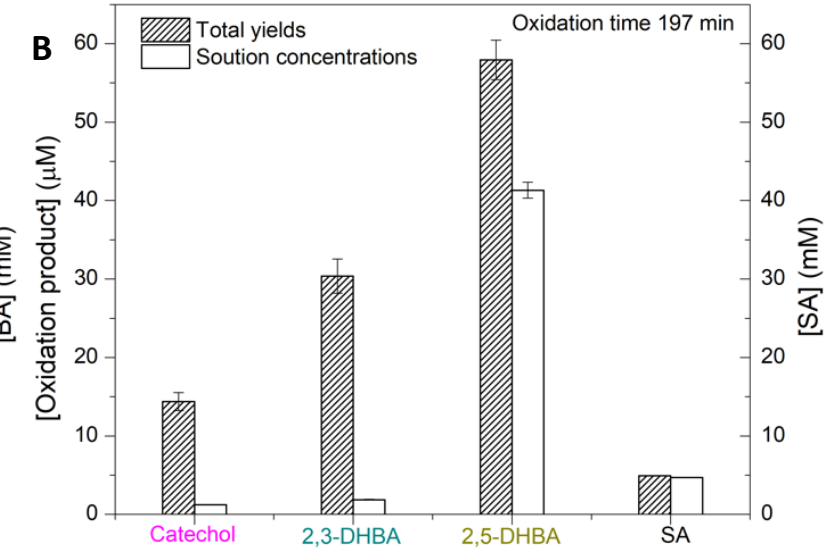

Figure S13. Recoveries of the sorbed products of the oxidized FeS in (A) BA oxidation and (B) SA oxidation by using $1 \mathrm{M}$ ascorbic acid for about $34 \mathrm{~h}$. Unless noted otherwise, $[\mathrm{FeS}]_{0}=0.9 \mathrm{~g} / \mathrm{L},[\mathrm{HEPES}]_{0}=20 \mathrm{mM},\left[\mathrm{NaHCO}_{3}\right]_{0}=$ $1 \mathrm{mM}, \mathrm{pH}_{0} 7.5,(\mathrm{~A})[\mathrm{BA}]_{0}=5.0 \mathrm{mM}$, (B) $[\mathrm{SA}]_{0}=5.0 \mathrm{mM}$. 


\section{S7. Competition experiment data}
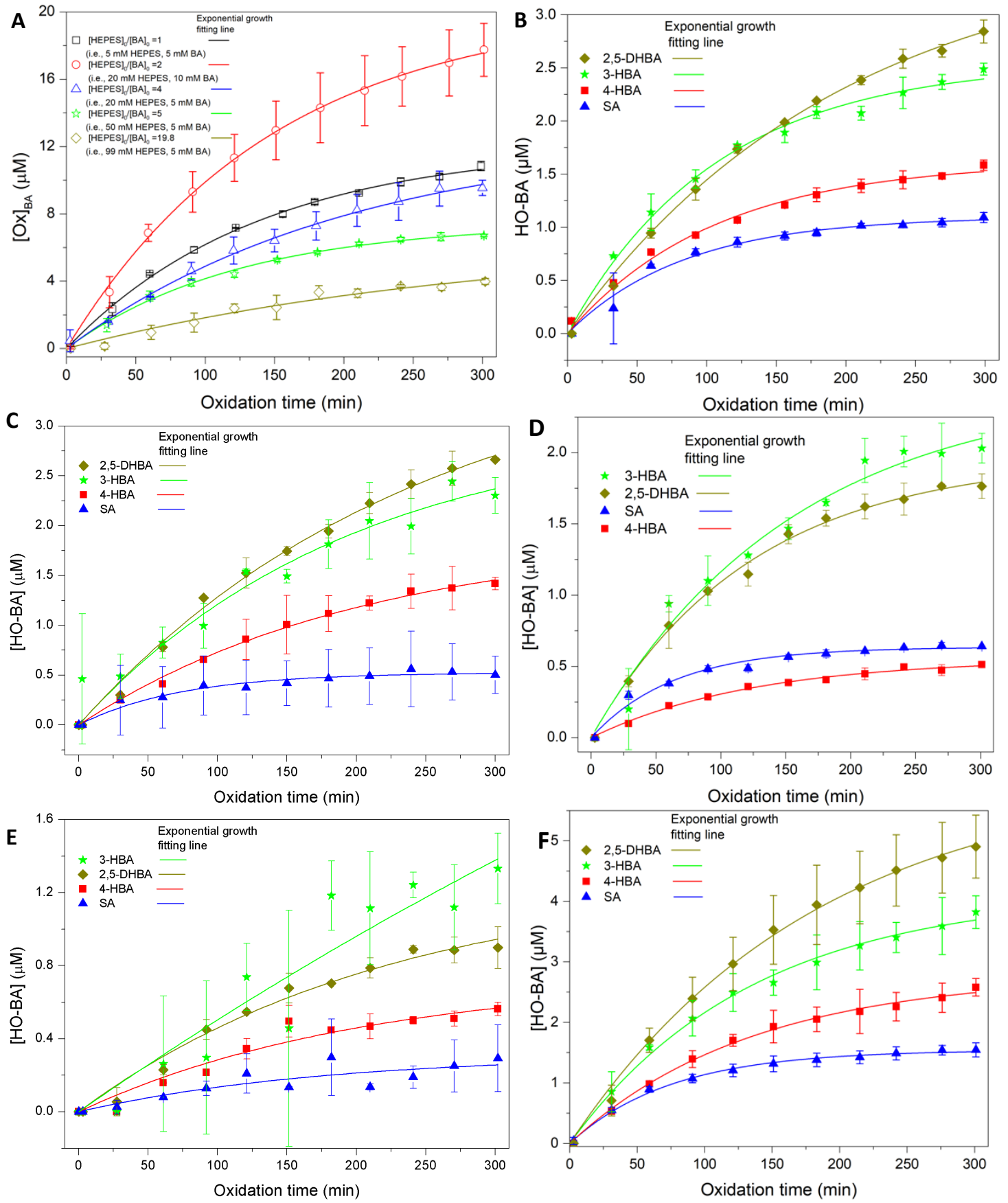

Figure S14. Oxidation of BA during FeS oxygenation under varied $[\mathrm{HEPES}]_{0} /[\mathrm{BA}]_{0}$ : (A) change of $[\mathrm{OX}]_{\mathrm{BA}} ;(\mathrm{B}-\mathrm{F})$ change of $[\mathrm{HO}-\mathrm{BA}]$. Unless noted otherwise, $[\mathrm{FeS}]_{0}=0.9 \mathrm{~g} / \mathrm{L}$, $\left[\mathrm{NaHCO}_{3}\right]_{0}=1 \mathrm{mM}, \mathrm{pH}_{0}$ 8.0. (B) $[\mathrm{HEPES}]_{0}=5 \mathrm{mM}$, $[B A]_{0}=5.0 \mathrm{mM}$; (C) $[\mathrm{HEPES}]_{0}=20 \mathrm{mM},[\mathrm{BA}]_{0}=5.0 \mathrm{mM}$; (D) $[\mathrm{HEPES}]_{0}=50 \mathrm{mM},[\mathrm{BA}]_{0}=5.0 \mathrm{mM} ;(\mathrm{E})[\mathrm{HEPES}]_{0}=99$ $\mathrm{mM},[\mathrm{BA}]_{0}=5.0 \mathrm{mM} ;(\mathrm{F})[\mathrm{HEPES}]_{0}=20 \mathrm{mM},[\mathrm{BA}]_{0}=10.0 \mathrm{mM}$. 

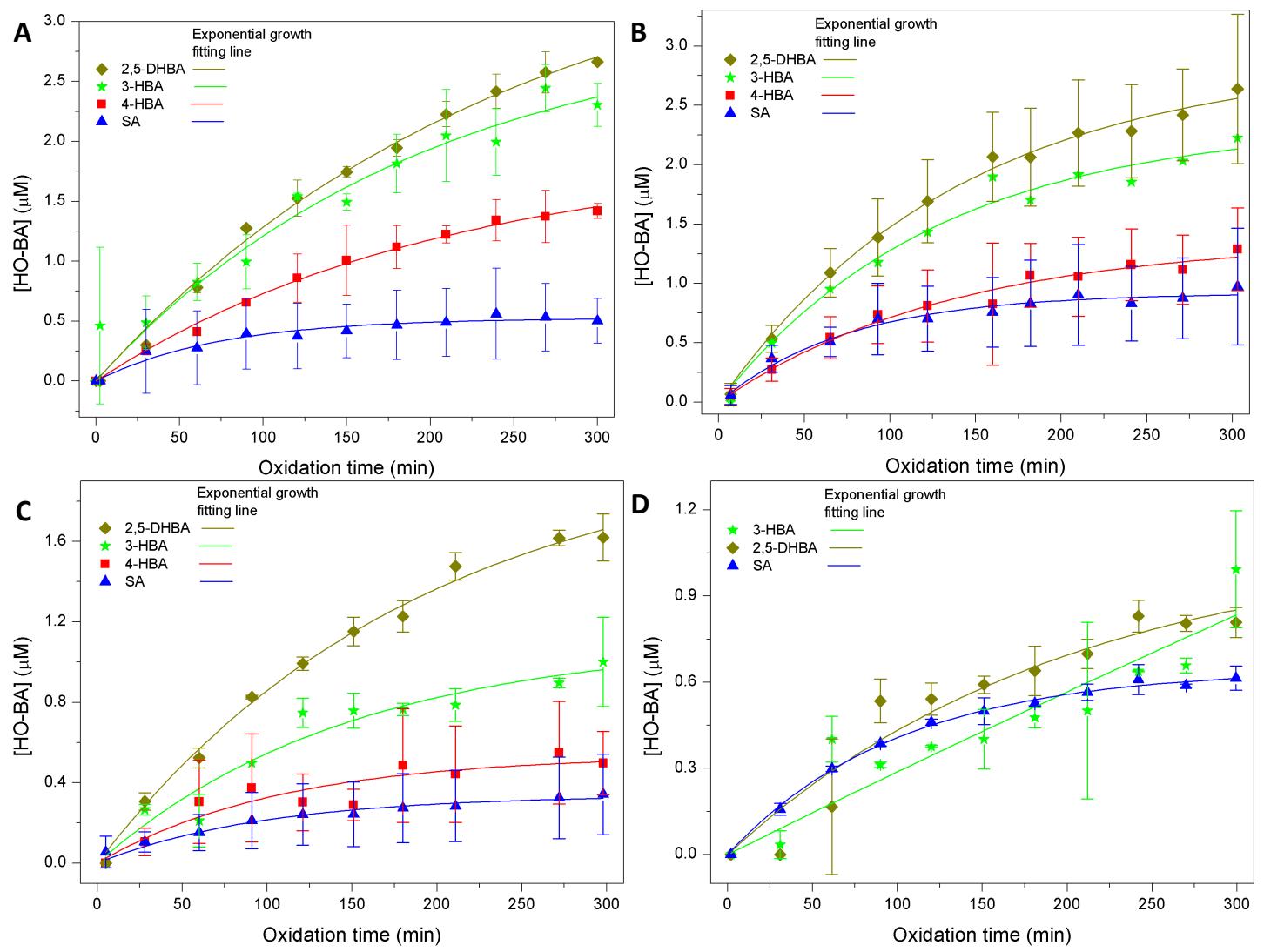

Figure S15. Oxidation of BA during FeS oxygenation in the presence of varied [TBA] $]_{0}$ (A) 0 , (B) 0.07, (C) 0.73 , (D) $3.14 \mathrm{M} .[\mathrm{FeS}]_{0}=0.9 \mathrm{~g} / \mathrm{L},[\mathrm{BA}]_{0}=5.0 \mathrm{mM},[\mathrm{HEPES}]_{0}=20 \mathrm{mM},\left[\mathrm{NaHCO}_{3}\right]_{0}=1 \mathrm{mM}, \mathrm{pH} \mathrm{H}_{0} 8.0$. 


\section{S8. Kinetic model details and fitting results}

Although we are unable to confirm the precise identity of the strong oxidant, nor the details of its formation, it is reasonable to assume that it is formed from the interaction of $\mathrm{FeS}$ and $\mathrm{O}_{2}$, i.e., from a reaction such as $\mathrm{FeS}+$ $\mathrm{O}_{2} \rightarrow \mathrm{Ox}+\mathrm{FeS}_{\mathrm{Ox}}$, where it is understood that $\mathrm{Ox}$ is localized to the surface of the mineral. Surface partitioning was included for species that we could experimentally measure (i.e., SA and 2,5-DHBA), however, an overall combined reaction is used for other species where partitioning information could not be determined. These reactions should be understood to be a combined reaction that includes an equilibrium with the surface, i.e., $S$ + surface $\rightleftharpoons \mathrm{S}$-surface (with equilibrium constant $K$ ) followed by the oxidation reaction S-surface $+\mathrm{Ox} \rightarrow \mathrm{Sox}+$ $\mathrm{FeS}_{\mathrm{Ox}}$ (rate constant $k_{\mathrm{ox}}$ ) with the modelled $k$ value a composite of both the equilibrium and oxidation reactions $\left(k_{\text {model }}=K[\right.$ surface $\left.] \times k_{\text {ox }}\right)$. Considering the surface is likely an iron oxide, we have taken the surface site concentration to be equal to $10 \%$ of the Fe concentration, which is typical for ferrihydrite. ${ }^{7}$ The process where FeS scavenges the oxidant has been modelled as a first order process, as the driving force for this reaction would be unlikely to vary proportionally to the FeS concentration, despite the stoichiometry, i.e.: $\mathrm{Ox}+\mathrm{FeS} \rightarrow \mathrm{FeS}_{\mathrm{Ox}}$ $\frac{d[\mathrm{Ox}]}{d t}=k[\mathrm{Ox}]$.
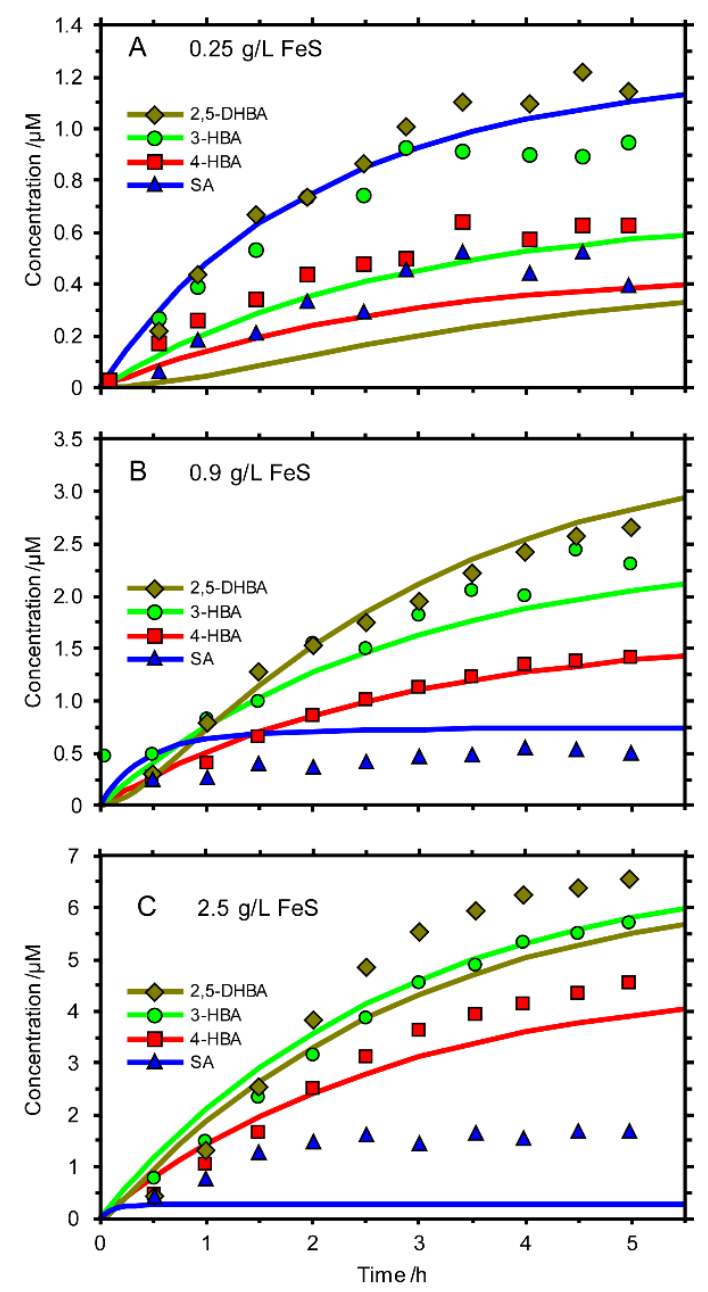

Figure S16. Oxidation of BA during FeS oxygenation under varied [FeS $]_{0}$ : (A) 0.25 , (B) 0.9, (C) $2.5 \mathrm{~g} / \mathrm{L}$. [BA $]_{0}=5.0$ $\mathrm{mM},[\mathrm{HEPES}]_{0}=20 \mathrm{mM},\left[\mathrm{NaHCO}_{3}\right]_{0}=1 \mathrm{mM}, \mathrm{pH}_{0}$ 8.0. Symbols are experimental data and lines are the kinetic model output. 

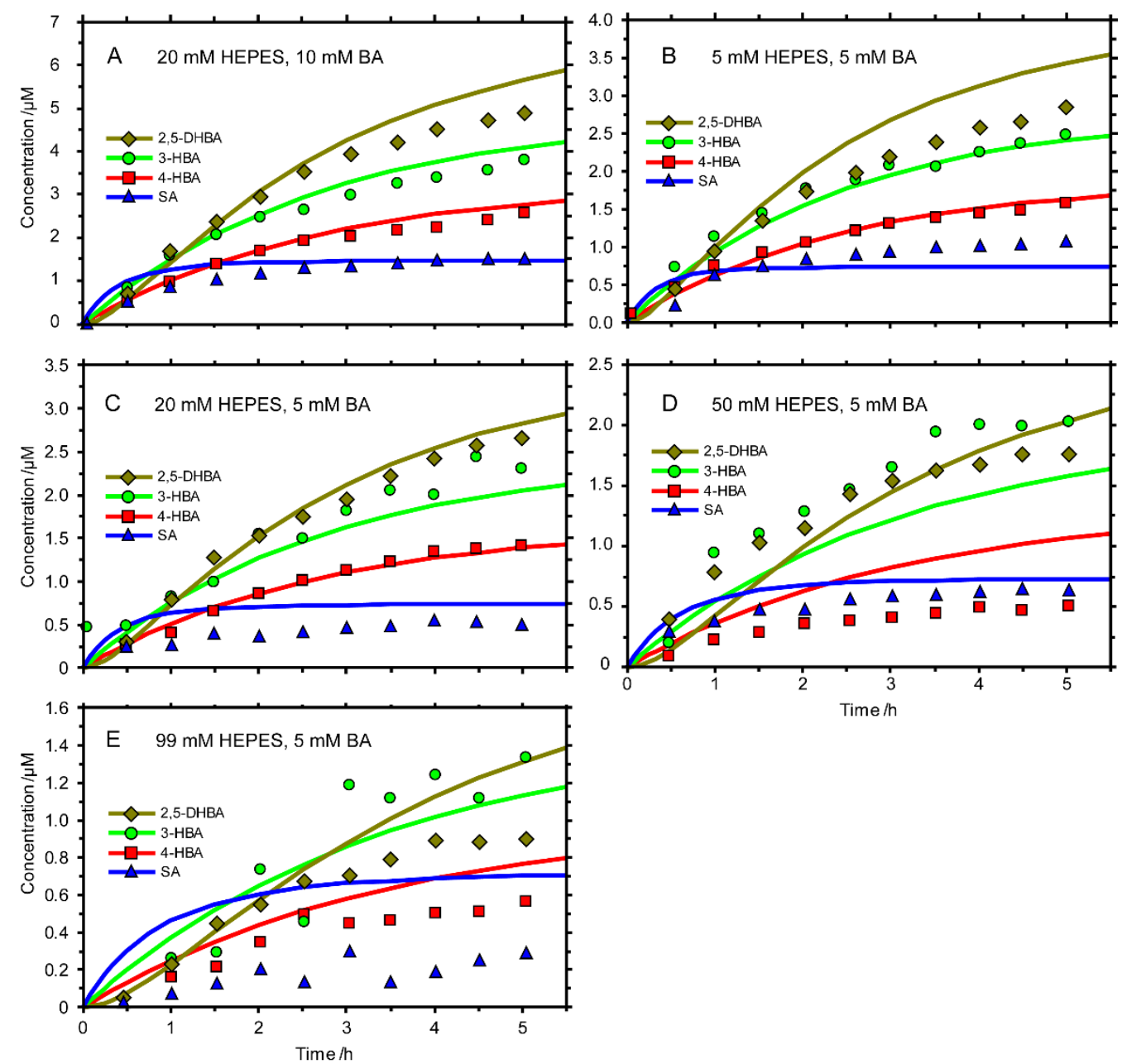

Figure S17. Oxidation of BA during FeS oxygenation under varied [HEPES $]_{0}$ and $[\mathrm{BA}]_{0}$. In all cases $[\mathrm{FeS}]_{0}=0.9$ $\mathrm{g} / \mathrm{L},\left[\mathrm{NaHCO}_{3}\right]_{0}=1 \mathrm{mM}, \mathrm{pH}_{0}$ 8.0. Panels $\mathrm{A}$ to $\mathrm{E}$ have HEPES and BA concentrations as labelled. Symbols are experimental data and lines are the kinetic model output. 

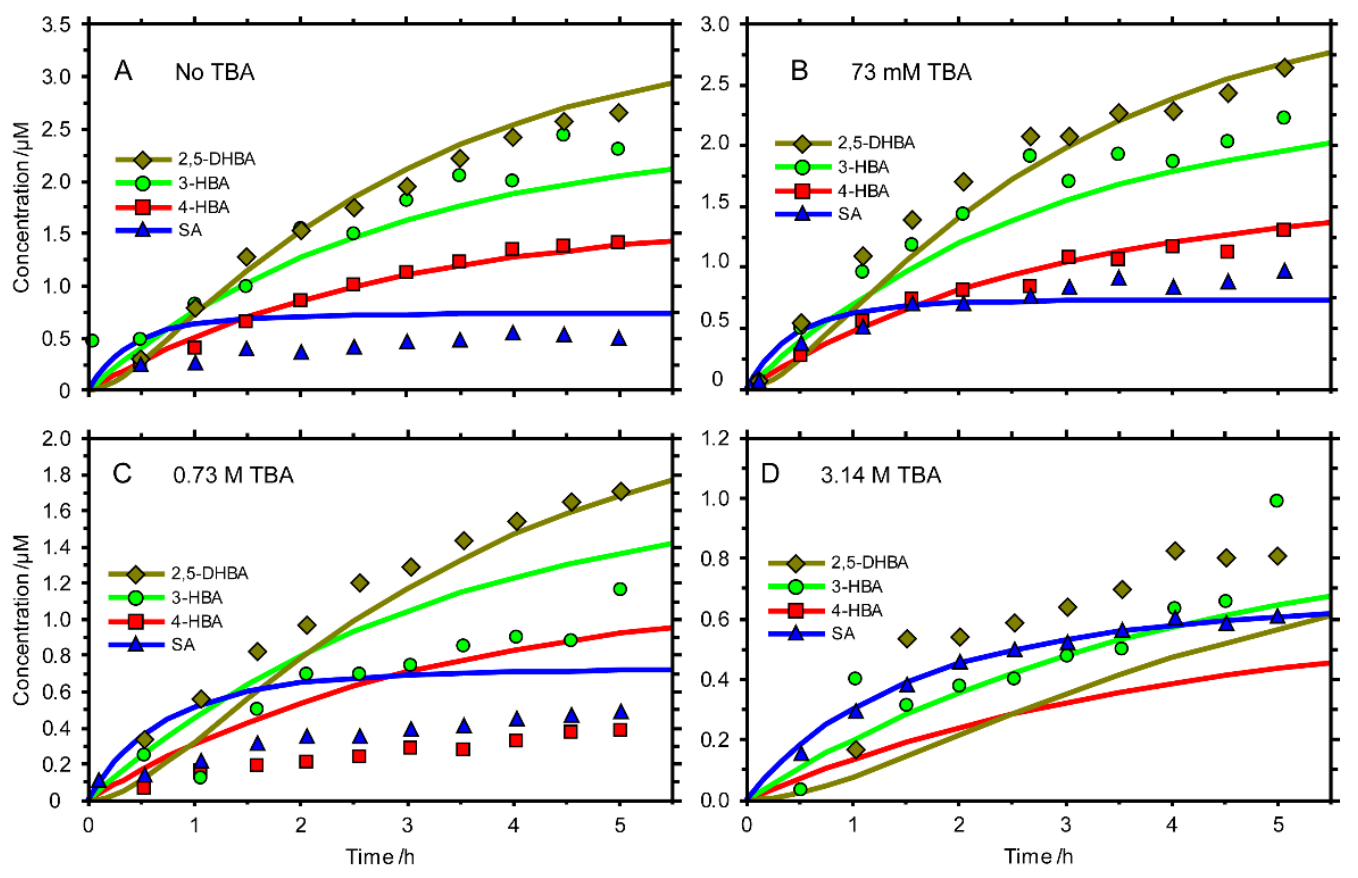

Figure S18. Oxidation of BA during FeS oxygenation in the presence of varied $[T B A]_{0}:(A) 0,(B) 0.07,(C) 0.73$, (D) $3.14 \mathrm{M}$. $[\mathrm{FeS}]_{0}=0.9 \mathrm{~g} / \mathrm{L},[\mathrm{BA}]_{0}=5.0 \mathrm{mM},[\mathrm{HEPES}]_{0}=20 \mathrm{mM},\left[\mathrm{NaHCO}_{3}\right]_{0}=1 \mathrm{mM}, \mathrm{pH}_{0} 8.0$. Symbols are experimental data and lines are the kinetic model output.

\section{REFERENCES}

1. Bompoti, N.; Chrysochoou, M.; Machesky, M., Surface structure of ferrihydrite: Insights from modeling surface charge. Chem. Geol. 2017, 464, 34-45.

2. Viollier, E.; Inglett, P. W.; Hunter, K.; Roychoudhury, A. N.; Van Cappellen, P., The ferrozine method revisited: $\mathrm{Fe}(\mathrm{II}) / \mathrm{Fe}(\mathrm{III})$ determination in natural waters. Appl. Geochem. 2000, 15, (6), 785-790.

3. Jones, A. M.; Collins, R. N.; Rose, J.; Waite, T. D., The effect of silica and natural organic matter on the Fe(II)-catalysed transformation and reactivity of Fe(III) minerals. Geochim. Cosmochim. Acta 2009, 73, (15), 44094422.

4. Kalyanaraman, B.; Ramanujam, S.; Singh, R. J.; Joseph, J.; Feix, J. B., Formation of 2,5-dihydroxybenzoic acid during the reaction between singlet oxygen $\left({ }^{1} \mathrm{O}_{2}\right)$ and salicylic acid: analysis by ESR oximetry and HPLC with electrochemical detection. J. Am. Chem. Soc. 1993, 115, (10), 4007-4012.

5. Wilkinson, F.; Helman, W. P.; Ross, A. B., Rate Constants for the Decay and Reactions of the Lowest Electronically Excited Singlet State of Molecular Oxygen in Solution. An Expanded and Revised Compilation. J. Phys. Chem. Ref. Data 1995, 24, (2), 663-677.

6. Xu, J.; Jordan, R. B., Kinetics and mechanism of the oxidation of 2,3-dihydroxybenzoic acid by iron(III). Inorg. Chem. 1988, 27, (25), 4563-4566.

7. Hanna, K., Sorption of two aromatic acids onto iron oxides: Experimental study and modeling. J. Colloid Interface Sci. 2007, 309, (2), 419-428. 